\title{
Rabelais et la question du sens, études réunies et publiées par Jean Céard et Marie-Luce Demonet, avec la collaboration de Stéphan Geongetit
}

\section{Michele Mastroianni}

\section{(2) OpenEdition}

\section{Journals}

Edizione digitale

URL: https://journals.openedition.org/studifrancesi/4625

DOI: $10.4000 /$ studifrancesi.4625

ISSN: 2427-5856

\section{Editore}

Rosenberg \& Sellier

\section{Edizione cartacea}

Data di pubblicazione: 1 avril 2012

Paginazione: 131

ISSN: 0039-2944

\section{Notizia bibliografica digitale}

Michele Mastroianni, «Rabelais et la question du sens, études réunies et publiées par Jean Céard et Marie-Luce Demonet, avec la collaboration de Stéphan Geongetit», Studi Francesi [Online], 166 (I | LVI) | 2012, online dal 30 novembre 2015, consultato il 19 novembre 2021. URL: http://

journals.openedition.org/studifrancesi/4625 ; DOI: https://doi.org/10.4000/studifrancesi.4625

Questo documento è stato generato automaticamente il 19 novembre 2021.

\section{c) $(9 \ominus$}

Studi Francesi è distribuita con Licenza Creative Commons Attribuzione - Non commerciale - Non opere derivate 4.0 Internazionale. 


\title{
Rabelais et la question du sens, études réunies et publiées par Jean Céard et Marie-Luce Demonet, avec la collaboration de Stéphan Geongetit
}

\author{
Michele Mastroianni
}

\section{NOTIZIA}

Rabelais et la question du sens, études réunies et publiées par Jean CÉARD et Marie-Luce DEMONET, avec la collaboration de Stéphan GEONGET, Genève, Droz, 2011 («Études Rabelaisiennes», t. XLIX), pp. 306.

1 Come sottolinea chiaramente Jean CÉARD nella sua Introduction (pp. 7-12), gli studi qui offerti (Atti del Colloque de Cerisy del 2002, su Rabelais) intendono, «attraverso un certo numero di analisi particolari, di interrogare l'idea di segno, fondandosi sulla riflessione preliminare che interpretare è proporre un senso a partire da segni raccolti nel testo, segni che sono pertanto considerati come indizi sia del senso che delle prove di questo senso». In questa analisi dell'opera rabelaisiana il criterio seguito è stato anzitutto quello di considerare il legame più o meno stretto che il segno ha con la fiction, a volte fermandosi al livello lessicale, a volte ponendosi nella prospettiva di decifrare il senso celato sotto il velo della fabula. Inoltre occorre segnalare che i vari studi non hanno come finalità di discutere le interpretazioni già formulate né di elaborare nuove interpretazioni, quanto piuttosto illustrare e attivare i procedimenti mediante i quali si elabora un'interpretazione.

2 I contributi qui raccolti sono i seguenti: Claude LA CHARITÉ, La disputation par signes et la 'philochirosophie' (pp. 15-36); Frank LESTRINGANT, Le souffle et le sens. À propos du Physétère ("Quart Livre», ch. 33-34) (pp. 37-58); Jacques BERCHTOLD, Les mouches et les mousses aux orifices du corps. Les niveaux de sens dans le chapitre $15 d u$ "Pantagruel" (pp. 59-73); Pierre 
Johan LAFFITTE, La disposition au sens d'une anecdote rabelaisienne ("Quart Livre», LXVII). Maistre François Villon, ou la construction d'une 'auctoritas' par le jeux des voix (pp. 75-97); Paul J. SмIтH, «Les âmes anglaises sont andouillettes». Nouvelles perspectives sur l'épisode des Andouilles ("Quart Livre», ch. 35-42) (pp. 99-111); Louis-Georges TIN, Le Pantagruelion. Réflexions sur la notion d'exégèse littéraire (pp. 113-124); Stéphan GEONGET, Les 'Y gregoys' de Rabelais (pp. 127-144); Myriam MARRACHE-GOURAUD, Cornes et cornemuses. Panurge architecte et maitre du sens (pp.145-160); Oumelbanine zHIRI, Le «Tiers Livre», le temps et le sens (pp. 161-174); Barbara C. BowEN, Sens et non-sens chez Bridoye (pp. 175-183); Véronique ZAERCHER-KECK, Réécriture et production du sens (pp.185-196); André TOURNON, Des croisements signalés. Mots et gestes sibyllins (pp.197-208); Marie-Luce DEMONET, Le sens littéral dans l'œuvre de Rabelais (pp. 211-236); Jean-François MAILLARD, La chimère d'un Rabelais kabbaliste (pp. 237-251); Gilles PoLIzzI, Le lieu du sens. Les réécritures de la scène initiatique dans la fiction rabelaisienne (pp. 253-270); Emmanuel NAYA, «Sustinere assensum, sustinere sensum». Gelées rabelaisiennes du sens (pp. 271-291).

Una volta di più (ed è l'interesse principale, forse, della presente miscellanea) appare evidente la molteplicità di letture di cui è passibile l'opera di Rabelais: letture che privilegiano le(s) haut(s) sens e letture che privilegiano il piacere della narrazione e dell'invenzione. Letture plurali, anche quando si cerca di decifrare il sens, letture in cui ritroviamo prospettive diverse, dall'evangelismo all'erasmismo all'esoterismo. Come ricorda giustamente Marie-Luce DEMONET nella sua Conclusion (pp. 293-295), i contributi del Colloque di Cerisy escono con un ritardo di dieci anni, e in questo decennio sono usciti libri e articoli importanti su Rabelais e, a volte, sugli argomenti specifici affrontati nel volume che recensiamo. Tuttavia il discorso qui presentato sulle polisemie del testo rabelaisiano fornisce materiale utilissimo d'indagine a tutt'oggi valido. 